\title{
Reforming Chinese teaching for cultivating students' key competencies
}

\author{
Hongmei Zhang \\ Second middle school in kangping county, Shenyang, China \\ 2297939903@qq.com
}

\begin{abstract}
Keywords: Educational reform, Key competencies, Chinese teaching, Integrated teaching mode, Teaching strategies
\end{abstract}

\begin{abstract}
The framework of key competencies and value for Chinese student's development requires that the education of students in the new era should cultivate the well-rounded people based on the principles of scientificity, contemporaneity, and nationality. The research objective of this paper is to reform traditional Chinese teaching and to carry out the practice of high-quality and efficient teaching for serving the cultivation of students' key competencies. The analysis results show Chinese subject playing a diffusive role, can be employed to develop the integrated teaching mode coupling diversified knowledge through exploring the effective teaching strategies among disciplines. The use of social tools is emphasized to build a teaching system inside and outside class for developing students' ability. Also, the improved multimedia teaching methods and campus education are underlined to create an educational environment that promotes students' key competencies. Also, six measures or findings were put forward for the cultivation of Chinese students' core qualities, which can provide a valuable reference for others implementing Chinese teaching reforming.
\end{abstract}

\section{Introduction}

Since the 1990s, the key competencies have become an essential issue in the field of worldwide education policy, practice and research, international organizations, and many countries or regions have to core literacy framework[1], such as the international organization for economic cooperation and development (OECD), the United Nations educational, scientific and cultural organization (UNESCO)[2], the European Union (EU)[3] and other international organizations, etc. In 2016, the overall framework of 'Chinese students' development of core literacy' was officially released [4], marking that China's future-oriented and international-oriented reform of primary education has sounded the trumpet. The framework requires that the education of students in the new era should be based on the basic principles of science, times and nationality, with the cultivation of 'well-rounded people' as the core, which can be divided into three aspects: cultural foundation, independent development, and social participation. The overall performances are the humanities, scientific spirit, society study, healthy life, responsibility, and innovation.

The cultivation of Chinese students' core qualities requires that the basic principles should be scientific, contemporary and national, the core should be the cultivation of 'well-rounded people', and the goal should be to have the necessary character and key ability to meet the needs of lifelong development and social development. In addition to cultivating students' abilities of literacy, reading, writing and oral communication, Chinese teaching is of great inclusiveness and radiation. In Chinese teaching, it can provide students with an environment of scientific cognition, a carrier of The Times and a channel for spiritual cultivation of national rejuvenation. Therefore, through Chinese teaching, it is an urgent task for Chinese teaching to promote all-round education and cultivate students' core qualities in the new era and under the new guidance. This topic focuses on the construction of a new model of Chinese subject teaching under the framework of the cultivation of students' core literacy, that is, to answer the question of how to update the teaching concept, reform the teaching methods and innovate the teaching methods in the grassroots Chinese subject teaching so as to realize the ultimate goal of the cultivation of students' core literacy.

In recent years, there has been some discussion on the cultivation of students' core quality in the educational circle. Especially after the release of the overall framework of "Chinese students' development of core literacy", the significance and implementation path of core literacy have become 
the focus of current education. Education departments and many schools have started to explore the implementation path of core literacy. In Chinese teaching, there are also a lot of research results and experience in the press. From the relationship between Chinese teaching and the cultivation of core literacy, how to realize the cultivation of scientific literacy in Chinese teaching, how to practice the development of thinking and cultural inheritance in Chinese teaching, how to embody the spirit of cultivating core literacy through curriculum teaching and other issues have been put forward. However, by sorting out the existing studies, it is not difficult to find that many educators focus on theoretical analysis and point-to-point research. So far, no effective model has been proposed for promotion.

From "Chinese students to develop the core quality" as the theme of 2016 China education mingde BBS, thousands of education scholars from home and abroad, the school principal to explore core literacy construction has been consensus on the connotation and the implementing measures, and always think the literacy education should be reflected in the whole school education teaching, its implementation is dependent on the curriculum reform, teacher training, and scientific evaluation. Unfortunately, there is still more research at the macro level and less at the micro level. However, the ultimate practitioner of this task -- grassroots educators still think less at present.

This paper conforms to the needs of the reform of core literacy in the new era, and through the integration of grassroots work experience, puts forward some new ideas and methods for discipline teaching under the framework of cultivating students' core literacy, and integrates them to form a set of practical teaching mode for educators to reference and promote.

\section{METHODS}

The main problem to be solved in the development of students' core literacy is "how to cultivate wellrounded people", whose goal is to equip students with the necessary character and key abilities to meet the needs of lifelong development and social development. In combination with the reality of China's education, it is to avoid the phenomenon of students' ability differentiation, personality certification and moral labeling, but to train students' perseverance, self-control, curiosity, sense of responsibility, courage and self-confidence as the main line, to improve students' ability to adapt to lifelong development and social development. Mapping to our education, namely the cultural foundation, independent development, social participation in three aspects, the comprehensive performance of humanity, scientific spirit, learning, healthy life, responsibility, practice, and innovation six qualities. In the exploration of the mode of Chinese subject education, we will also take this as the goal to construct a new mode of Chinese subject teaching under the framework of cultivating students' core literacy by integrating curriculum setting, teaching means, knowledge integration, extracurricular practice, face-to-face links, and other approaches. The details are as follows:

(1) Play the radiation role of Chinese subject to promote the integrated teaching mode of multiple knowledge. Specially, it is to pay attention to the relations and integration processes between Chinese subject with other subjects, and to strengthen the connection between the Chinese course content and the knowledge in English, mathematics, biology, social life, and other areas. By this, a system for improving students' core literacy is built, which can take the students in cycle education composed by different subject education and can convey the essence of science to students from different perspectives.

(2) Emphasize independent learning to construct the in-class and out-class teaching system for cultivating students' development ability. In Chinese teaching, the practice should be added in my mind, aiming to encourage students to learn and use social tools to carry out effective discussions and social surveys. In this period, independent work is required to complete learning tasks. Through their learning, students can increase the enthusiasm to explore unknown fields, and develop the ability to use social tools to solve problems independently and carry out practical innovation.

(3) Improve the teaching methods and cultivate environments to establish education environment required by the development of students' essential character and morals. In the process, it is needed to make full use of graphics, animation, video, and other media means to strengthen the teaching 
effect on the content about the spirit \& character cultivation, traditional culture, art appreciation, responsibility and mission in Chinese teaching. Through the work, an intensive education can be implemented to improve students' core literacy from several aspects of the background, origin, humanistic spirit, development trend and social environment. Meanwhile, it is expected that the elegant campus culture and colorful campus activities as the carrier, to promote students to form the necessary character and key ability for adapting to the present and future social development.

\section{FINDINGS}

\subsection{Refine the teaching objectives, one paper for one objective}

Chinese teaching materials are full of articles of both quality and beauty, which are excellent models for students to develop their core literacy. Thus, it is suggested to explore deeply the ideological and emotional connotation of the articles, and set the training target of "core literacy" according to the specific content of each class, for realizing one paper for one objective. In addition, we should also pay attention to the interdisciplinary between subjects, and strengthen the connection between Chinese course content and other subjects as English, mathematics, biology, social life so as to deliver the essence of science to students from different perspectives.

\subsection{Design classroom teaching activities to facilitate the cultivation of core quality}

In my Chinese class, a speech covering three minutes is always employed before class. The content of the speech is mainly the monthly reading (Chinese or English) assigned in the classic. The aim of this activity is to stimulate students' interest in reading, cultivate the habit of reading, and build the link of learning inside and outside the class. Our practical experiences indicate that through the threeyears speech before class from the beginning of students into junior high school, the reading habits and the speakability in public of most of the students were developed, and the benefits of reading are self-evident. Also, the speech before class is introduced to English class, stimulating each other, driving each other and the student's spoken English is getting better and better. In math class, the speech before class is represented as explaining the math problem, which not only can exercise their oral expression ability, but also can exercise students' logical thinking ability, and strengthen their control of knowledge. At present, a large number of 'little teachers' in different classes continue to emerge. In addition, group cooperative inquiry learning is carried out in all subjects, and various competitions emerge one after another. Giving full play to the main role and cooperative spirit of students, it is of great importance to cultivate students' humanistic feelings and aesthetic taste and enable students to learn happily and be good at learning.

\subsection{Deeply cultivate teaching materials to promote the level of problem orientation}

In teaching practice, it is found that there is a widespread, great importance and less-noticed problems in Chinese teaching in junior high school, which are that Chinese teaching content is just from the textbook. This leads to the teachers often take teaching materials (textbook) directly as the teaching content so that they have no thinking deeply on the problem what should be taught. Thus, the author thinks that a thorough study on the teaching content is required according to textbooks, by which the key contents of cultivating students' core literacy can be dug out. Furthermore, carefully setting guidance questions depending on the key contents will trigger students' active exploration and discussion, promote discipline integration, and improve the level of problem-oriented training.

\subsection{Grasp the main line before class and look back after class}

Nowadays, it is seen that many teachers concentrate on class teaching, which is gratifying. However, the after-class review work is often neglected by teachers. Many teachers complete their teaching tasks as soon as they finish their classes. The teaching plan is intact, and no new ink is left on the teaching notes. In fact, the after-class review or feedback is an indispensable step in the teaching process $^{[5]}$. It is as important as lesson preparation and basic skills. Therefore, it is suggested to teachers to review and reflect the teaching content in time after each class, due to the review or reflection can make us find out the significant points and shortcomings of teaching. Through 
analyzing the reasons, the advantage is maintained and the disadvantage is modified, and the teaching level will improve in a spiraling way.

\subsection{Listen to others to discipline the behavior}

To encourage self-knowledge and self-management of students and improve their physical and mental development, the weekly group meeting closely related to the content of core literacy cultivation is recommended in my work. For example, a theme class meeting about 'learn to appreciate' was convened. We discussed a subject, what kind of boys and girls do you appreciate? In the meeting, the characteristics of the appreciated boys and girls were listed, and the undesirable behaviors were also put forward. Especially, the sharp summary of the girls touched the boys all who said that they had the development direction on self-understanding, self-management, and self-development through the discussion.

\subsection{Learn to use social tools}

With the rapid development of society, the means of learning and teaching are changing with each passing day. Therefore, we must learn to use social tools in teaching. Some social tools provide many contents that cannot be achieved in class or functions that cannot be achieved in traditional teaching, which is very helpful for us to promote the improvement of students' learning effect and students' core literacy education.

\section{CONCLUSION}

The study puts forward an idea to reform traditional Chinese teaching for cultivating students' key competencies. The idea includes playing the radiation role of Chinese subject to promote the integrated teaching mode of multiple knowledge, emphasizing independent learning to construct the in-class and out-class teaching system for cultivating students' development ability and improving the teaching methods and cultivate environments to establish education environment required by the development of students' essential character and morals. In the exploration, some good measures have been found, for example (1) refine the teaching objectives, one paper for one objective; (2) design classroom teaching activities to facilitate the cultivation of core quality; (3) deeply cultivate teaching materials to promote the level of problem orientation; (4) grasp the main line before class and look back after class; (5) Listen to others to discipline the behavior; (6) Learn to use social tools. These measures have been confirmed in our teaching practice that they are very effective to improve the cultivation of students' core qualities.

\section{References}

[1] G. Falloon, A. Janson, R. Janson. Learning objects and the development of students' key competencies: A New Zealand school experience, Australasian Journal of Educational Technology, vol. 26, pp. 626-642.

[2] Cultural Organization. UNESCO ICT competency framework for teachers. Unesco, 2012.

[3] R. D. Crick. Key Competencies for Education in a European Context: Narratives of Accountability or Care, European Educational Research Journal, vol. 7, pp. 311-318.

[4] J. Li. Educational Policy Development in China for the 21st Century: Rationality and Challenges in a Globalizing Age, Chinese Education \& Society, vol. 50, pp. 133-141.

[5] D. Carless and D. Boud. The development of student feedback literacy: enabling uptake of feedback, Assessment \& Evaluation in Higher Education, vol. 43, pp. 1315-1325. 